\title{
Biochars reduce irrigation water sodium adsorption ratio
}

\author{
Saima Awan ${ }^{1} \cdot$ James A. Ippolito ${ }^{2}$. J. L. Ullman ${ }^{3} \cdot$ Kamran Ansari $^{1} \cdot$ Liqiang Cui $^{2,4} \cdot$ A. A. Siyal ${ }^{1}$
}

Received: 27 July 2020 / Accepted: 7 October 2020 / Published online: 12 November 2020

(c) The Author(s) 2020

\begin{abstract}
Irrigation water quality plays a vital role in sustaining crop productivity and feeding a growing world population. In many countries, continued agricultural water reuse can lead to greater water-soluble salt concentrations, and in particular $\mathrm{Na}$; finding means by which irrigation water $\mathrm{Na}$, and thus sodium adsorption ratios (SAR), can be reduced would reduce the rate at which soil sodification occurs. Four biochars, containing a variety of organic functional groups and electrochemistries, were examined for their potential to sorb and remove $\mathrm{Na}$ from simulated irrigation water, and subsequently reduce water SAR. Two batch experiments examined the role that wheat straw biochar, lodgepole pine biochar, Kentucky bluegrass biochar, and hemp biochar played in terms of sorbing sodium over time or application rate. Of the four biochars examined, hemp biochar had the lowest oxidation-reduction potential (ORP; 0-100 mV), sorbed the greatest Na amount (up to $923 \mathrm{mg} \mathrm{kg}^{-1}$ ), and released $\mathrm{Ca}$ and $\mathrm{Mg}$ (up to 115 and $63 \mathrm{mg} \mathrm{kg}^{-1}$, respectively) into solution, all of which led to a significant reduction in water SAR (from 8.8 to $7.3 ; 17 \%$ decrease). Sodium sorption onto hemp biochar better fit a Langmuir versus a Freundlich isotherm, yet followed a pseudo-second-order model better than a pseudo-first-order kinetic model. The data suggest that $\mathrm{Na}$ ions formed a monolayer on the hemp biochar surface, influenced by associations with $\pi$ electrons, but given time the $\mathrm{Na}$ ions may diffuse into biochar pores or more slowly interact with biochar-borne $\pi$ electrons. Hemp biochar shows promise in reducing the SAR of Na-impacted waters. Future investigations should focus on additional laboratory, greenhouse, and field trials with hemp biochar and other biochars designed to have similar or superior properties for sorbing excess irrigation water $\mathrm{Na}$ and improving crop growth.
\end{abstract}

Keywords Biochar $\cdot$ Na-containing irrigation water $\cdot$ Oxidation-reduction potential $\cdot$ Sodium sorption $\cdot \pi$ Electrons

\section{Introduction}

Clean water is arguably the most important natural resource for fulfilling basic life requirements, yet clean water is under constant threat globally. The present world population is projected to be 8.6 billion by the year $2030,9.8$ billion by

James A. Ippolito

jim.ippolito@colostate.edu

1 US-Pakistan Center for Advanced Studies in Water, Mehran University of Engineering and Technology Jamshoro, Sindh 76090, Pakistan

2 Department of Soil and Crop Sciences, Colorado State University, Fort Collins 80523, USA

3 Department of Civil and Environmental Engineering, University of Utah, Salt Lake City 84112, USA

4 School of Environmental Science and Engineering, Yancheng Institute of Technology, No. 211 of Jianjun Road, Yancheng 224051, China
2050, and 11.2 billion by 2100 (United Nations 2017). This tremendous population increase will demand more than a $50 \%$ increase in food supply to meet population needs (Godfray et al. 2010; Mueller et al. 2012), undoubtedly requiring greater freshwater supplies. Freshwater use alone has increased nearly sixfold since 1900, with upwards of 350 billion $\mathrm{m}^{3}$ of freshwater used annually for agricultural purposes in countries such as the U.S., China, India, and Pakistan (Ritchie and Roser 2018); 70\% of global freshwater withdrawals are accounted for agriculture (FAO 2017). Among the threats to agricultural freshwater use is agriculture itself.

Agricultural brackish drainage and leaching water production have increased proportionally to increased irrigation water needs (FAO 2017). When waters are used multiple times within downstream agroecosystems, soil and water salinization and sodium accumulation may occur in conjunction with a rapid decline in agricultural productivity. These effects tend to be more pronounced in arid and semi-arid regions. Actions such as the Colorado River Basin Salinity 
Control Act (Congress.gov 1974) have been enacted to protect arid, southwestern U.S. water quality against (among other things) increasing salinity and subsequent agricultural losses when using such saline waters; these actions may not always be effective. Phillips et al. (2003) noted that total dissolved solids (TDS) increased from 40 to $>2000 \mathrm{mg} \mathrm{L}^{-1}$ over the $1200 \mathrm{~km}$ length of the south-western U.S. Rio Grande River; a combination of evapotranspiration losses and flushing of soil salts via irrigation were contributing factors. Increasing TDS along the Rio Grande River has likely caused producers to alter agroecosystems to crops that can tolerate greater TDS and salinity (e.g., from onion and lettuce with tolerances of $\sim 900 \mathrm{mg} \mathrm{L}^{-1}$ TDS threshold, to cotton with a tolerance of $\sim 6400 \mathrm{mg} \mathrm{L}^{-1}$ TDS threshold; Michelsen et al. 2009; U.S. Bureau of Land Reclamation 2010). In Pakistan, Qureshi et al. (2008) estimated a 25\% crop production loss due to similar downstream irrigation water salinity issues, equating to $\sim 250$ million USD per year. If irrigation water salinity and/or sodicity is too high for a desired crop, and cropping systems cannot be altered, a method to reduce water salinity or sodicity is needed.

Removing salinity or salts from irrigation waters is not impossible but may be costly or require additional land. Direct water desalinization (Kaner et al. 2017), desalinization through wetland plants (Yang et al. 2015), creation of desalting facilities (Marshall 1985), micro- or ultra-filtration in conjunction with reverse osmosis (Abulnour et al. 2002), electrodialysis in combination with ion exchange resins and activated carbon (Abulnour et al. 2002), and passing or forcing water through relatively small (e.g., $5 \mu \mathrm{m})$ membrane filters followed by activated charcoal filters (Ormbsy 1985) have been explored. The work described by Abulnour et al. (2002) and Ormbsy (1985), focused on activated charcoal use and piqued our interest in the potential use of biochar for reducing irrigation water salinity.

Biochars are carbonaceous materials produced via biomass pyrolysis at relatively low temperatures $\left(400-700^{\circ} \mathrm{C}\right)$ in limited oxygen environments (Lehmann and Joseph 2009). Biochars have been proven effective for improving various aspects of soil quality, and in some instances have been shown to positively alter soil salinity relationships and have improved plant growth. For example, Akhtar et al. (2015) showed that biochar (5\% w:w) was able to sorb $\mathrm{Na}$ and increase potato yield. Rezaie et al. (2019) noted that applying $2.5 \%$ biochar to soil (w:w), then irrigating with water having an electrical conductivity (EC) of $5 \mathrm{dS} \mathrm{m}^{-1}$, helped to improve faba bean yield. Elshaikh and She (2018) applied 0,5 , and $10 \%$ biochar to soil, and then irrigated with increasing $\mathrm{NaCl}$ containing solutions (up to $7.0 \mathrm{dS} \mathrm{m}^{-1}$ ). The authors noted that okra yield was maintained when using $10 \%$ biochar with irrigation waters up to $4 \mathrm{dS} \mathrm{m}^{-1}$. She et al.
(2018) found a similar $\mathrm{Na}$ ion sorption response with tomatoes when grown in soils with increasing biochar rates (up to $8 \%$ by wt.) and irrigated with saline waters (up to $3 \mathrm{dS} \mathrm{m}^{-1}$ ). Yang et al. (2019) noted that applying 5\% biochar to soil, and allowing phreatic water evaporation to occur, increased soil water holding capacity while decreasing the sodium adsorption ratio (SAR) and surface soil salinity.

The biochar-Na sorption studies above attempted to elucidate mechanisms behind Na sorption onto biochar surface. Biochar-Na sorption mechanisms ranged from essentially no explanation, to general preferential sorption, ion sorption, improved soil cation exchange capacity, or $\mathrm{Na}$ exchange with biochar-borne $\mathrm{Ca}$ and $\mathrm{Mg}$ ions. The major explanation missing from the above studies is that biochars can contain highly structured, aromatic compounds that induce electronegativity in the form of delocalized $\pi$ electrons (Miles et al. 2016). Biochars tend to be more electrochemically active than the original feedstock (Yuan et al. 2017), with biochar electron donating capacity likely due to the presence of phenolic compounds (Klüpfel et al. 2014). This electronegativity may effectively sorb soft base cations (e.g., Na) to a greater extent than hard base cations (e.g., $\mathrm{Ca}$ and $\mathrm{Mg}$ ), due to the weak hydration and relatively large radii of soft base cations; hard base cations may induce weak cation $-\pi$ electron interactions because of their high hydrated energies (Zhu et al. 2004), and thus they are less effectively sorbed by biochar delocalized $\pi$ electrons. A biochar electronegativity-Na interaction is the premise behind the current study.

The above work illustrates that biochars may play a role in mitigating salinity or sodicity when placed in soils. To date, however, we have been unable to find any information regarding the direct use of biochar for reducing irrigation water sodium concentrations. The objective of this study was to investigate the ability of biochars with varying electronegativity to reduce the sodicity of irrigation water. Our hypothesis was that the greater electronegativity, the greater likelihood of $\mathrm{Na}$ adsorption by biochar, and the greater reduction in water SAR.

\section{Methods and materials}

\subsection{Synthetic irrigation water and biochar creation}

Simulated irrigation water was created in the lab, based on the median $\mathrm{Na}, \mathrm{Ca}, \mathrm{Mg}, \mathrm{SO}_{4}$, and $\mathrm{Cl}$ concentrations in irrigation waters obtained from feeders, canals, and groundwater sources from the Sindh Province, Pakistan. Data were collected through the Salinity Control and Reclamation Project, through the Pakistan Water and Power Development Authority, with data provided by Dr. Kamran Ansari (personal 
communication; most sampling locations outlined here https ://irrigation.sindh.gov.pk/irrigation-network were used in median $\mathrm{Na}, \mathrm{Ca}, \mathrm{Mg}, \mathrm{SO}_{4}$, and $\mathrm{Cl}$ concentration determinations). The simulated irrigation water consisted of $3.70 \mathrm{~g}$ of $\mathrm{Na}_{2} \mathrm{SO}_{4}, 0.59 \mathrm{~g}$ of $\mathrm{CaCl}_{2} \cdot 2 \mathrm{H}_{2} \mathrm{O}$ and $1.02 \mathrm{~g} \mathrm{MgCl}_{2} \cdot 6 \mathrm{H}_{2} \mathrm{O}$ in $4 \mathrm{~L}$ of deionized water, or 270, 42, 28, 630, and $150 \mathrm{mg} \mathrm{L}^{-1}$ of $\mathrm{Na}, \mathrm{Ca}, \mathrm{Mg}, \mathrm{SO}_{4}$, and $\mathrm{Cl}$, respectively.

Four biochars, derived from wheat straw $\left(450{ }^{\circ} \mathrm{C}\right)$, lodgepole pine $\left(700{ }^{\circ} \mathrm{C}\right)$, Kentucky bluegrass $\left(500{ }^{\circ} \mathrm{C}\right)$ and hemp stalks $\left(500{ }^{\circ} \mathrm{C}\right)$, were used for the study. All biochars were analyzed for total $\mathrm{C}$ and $\mathrm{N}$ via dry combustion (Nelson and Sommers 1996), and total elemental analyses were determined by an $\mathrm{HClO}_{4}-\mathrm{HNO}_{3}-\mathrm{HF}-\mathrm{HCl}$ digestion (Soltanpour et al. 1996) with data presented in Table 1. Triplicate biochar samples were also tested for oxidation-reduction potential (ORP) over a 1 -week period by adding $30 \mathrm{~mL}$ of deionized water to $1.00 \mathrm{~g}$ biochar in a $50 \mathrm{~mL}$ beaker, allowing to sit lightly covered with parafilm at room temperature, and measuring ORP over time; a deionized water control was also utilized. Finally, after oven drying at $105^{\circ} \mathrm{C}$ for $12 \mathrm{~h}$, biochar organic functional groups were characterized using fourier transform infrared spectroscopy (FTIR).

\subsection{Batch adsorption experiments}

An initial biochar screening, batch adsorption experiment using a constant biochar and simulated irrigation water quantities was performed. In triplicate $50 \mathrm{~mL}$ centrifuge tubes, $0.50 \mathrm{~g}$ of each biochar and $25 \mathrm{~mL}$ of simulated irrigation water were added, lightly capped, and allowed to sit undisturbed on the lab counter for 1, 2, 4, 8, 16, 24, 96, and $168 \mathrm{~h}$. Following each time period, tubes were destructively sampled by centrifuging for $10 \mathrm{~min}$, the liquid filtered through Whatman \#1 filter paper, and then the solutions were analyzed for $\mathrm{Na}, \mathrm{Ca}$, and $\mathrm{Mg}$ concentrations via

Table 1 Biochar total elemental analyses

\begin{tabular}{lllll}
\hline Parameter & $\begin{array}{l}\text { Wheat } \\
\text { straw } \\
\text { biochar }\end{array}$ & $\begin{array}{l}\text { Lodgepole } \\
\text { pine bio- } \\
\text { char }\end{array}$ & $\begin{array}{l}\text { Kentucky } \\
\text { bluegrass } \\
\text { biochar }\end{array}$ & $\begin{array}{l}\text { Hemp } \\
\text { stalk } \\
\text { biochar }\end{array}$ \\
\hline $\mathrm{C}(\%)$ & 54.6 & 95.2 & 41.5 & 76.2 \\
$\mathrm{~N}(\%)$ & 1.20 & 0.41 & 2.26 & 0.82 \\
$\mathrm{Na}\left(\mathrm{mg} \mathrm{kg}^{-1}\right)$ & 353 & 724 & 26,100 & 1980 \\
$\mathrm{Ca}\left(\mathrm{mg} \mathrm{kg}^{-1}\right)$ & 6440 & 554 & 17,900 & 12,800 \\
$\mathrm{Mg}\left(\mathrm{mg} \mathrm{kg}^{-1}\right)$ & 2980 & 2530 & 7310 & 8210 \\
$\mathrm{P}\left(\mathrm{mg} \mathrm{kg}^{-1}\right)$ & 398 & 4300 & 1950 & 16,400 \\
$\mathrm{~K}\left(\mathrm{mg} \mathrm{kg}^{-1}\right)$ & 2180 & 4150 & 24,200 & 8840 \\
$\mathrm{Fe}\left(\mathrm{mg} \mathrm{kg}^{-1}\right)$ & 183 & 72.4 & 5640 & 854 \\
$\mathrm{Zn}\left(\mathrm{mg} \mathrm{kg}^{-1}\right)$ & 15.2 & 18.4 & 27.8 & 90.0 \\
$\mathrm{Mn}\left(\mathrm{mg} \mathrm{kg}^{-1}\right)$ & 619 & 52.3 & 182 & 688 \\
$\mathrm{Cu}\left(\mathrm{mg} \mathrm{kg}^{-1}\right)$ & 6.30 & 2.11 & 16.2 & 23.1 \\
\hline
\end{tabular}

inductivity coupled plasma-optical emission spectroscopy (ICP-OES).

The amount of ion adsorbed per unit mass (mg cation $\mathrm{g}^{-1}$ biochar) was determined using the following equation:

$q_{e}=\frac{\left(C_{o}-C_{e}\right)}{m} \times V \times 1000$,

where $C_{o}$ is initial ion concentration and $C_{e}$ are the final ion concentrations in $\mathrm{mg} \mathrm{L}^{-1}, V$ is the solution volume in $\mathrm{L}$, and $m$ is the biochar (e.g., adsorbent) mass in g. The sodium adsorption ratio (SAR) was also determined using the following equation:

$\mathrm{SAR}=\frac{\mathrm{Na}^{+}}{\sqrt{\frac{\mathrm{Ca}^{2+}+\mathrm{Mg}^{2+}}{2}}}$,

with all cation concentrations expressed in meq $\mathrm{L}^{-1}$.

After evaluating results of the above experiment, a second adsorbent-dose batch experiment was carried out using only the hemp biochar. In triplicate $50 \mathrm{~mL}$ centrifuge tubes, $0.25,0.50,1,1.5,2 \mathrm{~g}$ of hemp biochar, and $25 \mathrm{~mL}$ of simulated irrigation water were added, lightly capped, and allowed to stand for $1 \mathrm{~h}$. After $1 \mathrm{~h}$, the tubes were centrifuged for $10 \mathrm{~min}$, the liquid was filtered through a $0.45 \mu \mathrm{m}$ membrane filter, and analysed for EC, ORP, cation concentrations, and the amount of ion adsorbed per unit mass and SAR as described above.

Statistical analysis was performed on all treatments and time solution chemistry data was collected using the Proc GLMmodel in SAS version 9.4 (SAS Institute 2012). We tested our hypotheses using an $\alpha=0.05$, and when significance was present, a Tukey adjusted pairwise comparison tested was used to highlight differences (SAS Institute, 2013). All figures were created using Sigma Plot 13.0.

\subsection{Hemp biochar adsorption isotherms and kinetics}

Data from the increasing hemp biochar application rate adsorption experiment were analysed using Langmuir and Freundlich models. The Langmuir isotherm model, considered to account for monolayer formation between sorbent and sorbate (Langmuir 1916), and the Freundlich isotherm model, considered to account for multilayer formation between sorbent and sorbate (Limousin et al. 2007), were utilized. The linear Langmuir isotherm model is defined by the equation: 
$\frac{C_{e}}{q_{e}}=\frac{1}{Q_{\max } b}+\frac{C_{e}}{Q_{\max }}$,

where $C_{e}$ is the equilibrium concentration $\left(\mathrm{mg} \mathrm{L}^{-1}\right), q_{e}$ is the amount of sorption $\left(\mathrm{mg} \mathrm{L}^{-1}\right), Q_{\max }$ is the sorption capacity and $b$ is the affinity of sorption. The linear Freundlich isotherm model is defined by the equation:

$\log q_{e}=\log K f+\left(\frac{1}{n}\right) \log C_{e}$,

where $q_{e}$ is equal to amount of sorption at equilibrium state, $C_{e}$ is equal to equilibrium concentration of sorbate, $K f$ is the adsorption capacity and $1 / n$ is the heterogeneity factor.

Data from the hemp biochar adsorption experiment over time were analysed using traditional kinetics models, with sorption kinetics typically used to determine sorption capacity. Two different kinetic models were used, the pseudo-first-order model to describe physisorption, and the pseudo-second-order model to describe chemisorption. The pseudo-first-order model is defined as

$\operatorname{Ln}\left(q_{e}-q_{t}\right)=\ln q_{e}-K_{1} \times t / 2.303$,

where $q_{e}=$ maximum $\mathrm{Na}$ adsorbed (in $\mathrm{mg} \mathrm{g}^{-1}$ biochar), $q_{t}=$ the amount of $\mathrm{Na}$ adsorbed at particular time (in $\mathrm{mg} \mathrm{g}^{-1}$ biochar), and $K_{1}$ is pseudo-first-order rate constant. The pseudo-second-order model is defined as

$t / q_{t}=1 / K_{2 q e 2}+t / q_{e}$,

where $K_{2}$ is the pseudo-second-order rate constant.

\section{Results and discussion}

\subsection{Biochar ORP and fourier transform infrared spectrometry (FTIR) analysis}

The ORP of biochars was measured over a 1-week period prior to batch experiments. All four biochars were more electronegative as compared to the deionized water control, with the ORP decreasing in the order of wheat straw biochar $>$ lodgepole pine biochar $>$ Kentucky bluegrass biochar $\geq$ hemp biochar (Fig. 1). Biochars are typically negatively charged, with biochar electronegativity due in part to negative surface charge (Xie et al. 2015) and functional groups present (Oliveira et al. 2017). Biochars predominantly sorb metals via ion exchange (Uchimiya et al. 2011a, b), with exchange affected by the presence of biochar $\pi$ electrons $(\mathrm{C}=\mathrm{C})$, proton exchange, and ligand binding (Uchimiya et al. 2012). Thus, greater surface negative charge (in combination with functional groups present, described below), as with Kentucky bluegrass and hemp biochars, could theoretically attract greater cation concentrations as compared to less negatively charged biochars. If irrigation waters are impacted by $\mathrm{Na}$, the concept of $\mathrm{Na}$ ion electrostatic attraction by highly negative biochars (e.g., Zhu et al. 2004) might be pursued as a means of reducing irrigation water SAR.

Biochars were examined via FTIR analysis to identify functional groups present (Fig. 2). All four biochars exhibited $\mathrm{O}-\mathrm{H}$ stretching in the $3430 \mathrm{~cm}^{-1}$ region, indicative of $\mathrm{H}_{2} \mathrm{O}$ molecules of loose intensity (Keiluweit et al. 2010). Wheat straw biochar (Fig. 2a) contained:
Fig. 1 Oxidation-reduction potential of wheat straw, lodgepole pine, Kentucky bluegrass, and hemp stalk biochar, over time

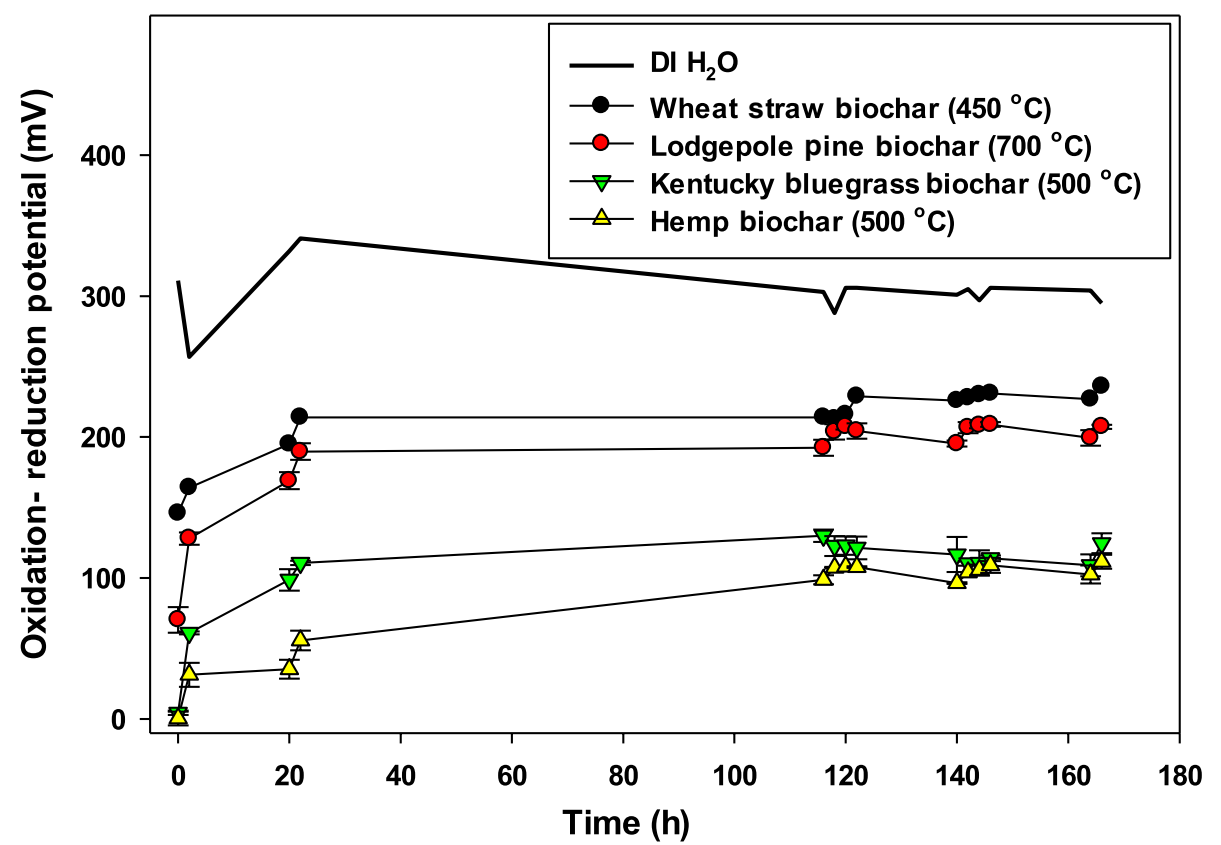



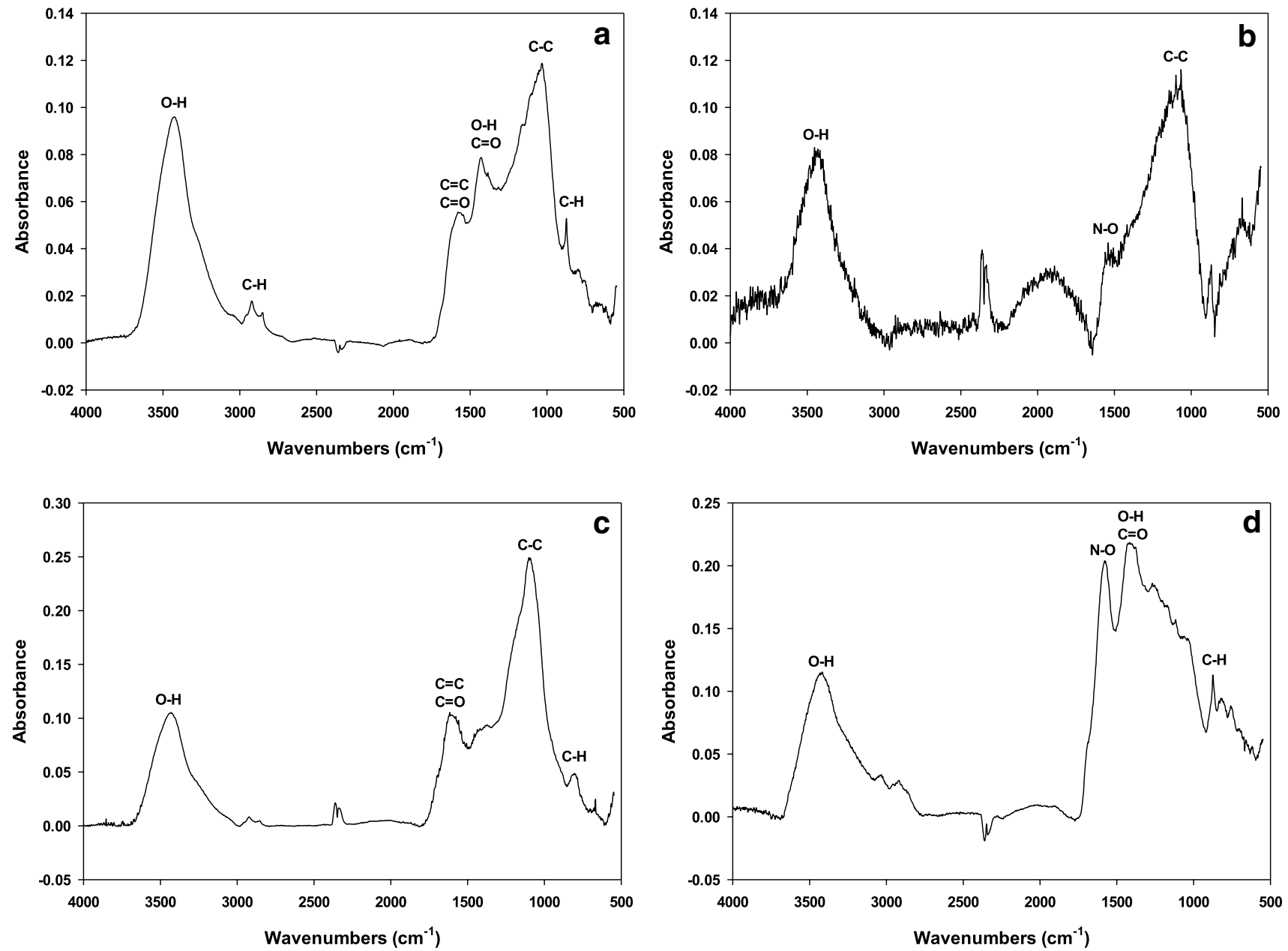

Fig. 2 The FTIR spectrum of a wheat straw, b lodgepole pine, $\mathbf{c}$ Kentucky bluegrass, and $\mathbf{d}$ hemp stalk biochar

aliphatic structures (C-H stretching; 2845-2924 $\mathrm{cm}^{-1}$ ); aromatic structures, ketones, anhydrides, esters, and the presence of carboxylic $\mathrm{C}$, or the presence of carbonaceous materials $(\mathrm{C}=\mathrm{C}$ and $\mathrm{C}=\mathrm{O}$ stretching; 1617 and $1630 \mathrm{~cm}^{-1}$ ); phenolic (i.e., aromatic) or ketone structures (O-H bending or $\mathrm{C}=\mathrm{O}$ stretching, respectively; 1405 and $\left.1430 \mathrm{~cm}^{-1}\right)$; undecomposed cellulosic and ligneous $\mathrm{C}\left(\mathrm{C}-\mathrm{C} ; \sim 1034 \mathrm{~cm}^{-1}\right)$; and lone aromatic $\mathrm{C}-\mathrm{H}$ out of the plane of vibration $\mathrm{CO}_{3}$ or $\mathrm{NO}_{3}$ (stretching between 804 and $870 \mathrm{~cm}^{-1}$ ) (Cui et al. 2019; Keiluweit et al. 2010; LibreTexts 2020; von Gunten et al. 2017). Lodgepole pine biochar (Fig. 2b) contained: N-O asymmetric stretching $\left(1540 \mathrm{~cm}^{-1}\right)$; and $\mathrm{C}-\mathrm{C}$ alcoholic group stretching (1029-1169 $\mathrm{cm}^{-1}$ ) (LibreTexts 2020). Kentucky bluegrass biochar (Fig. 2c) contained: aromatic structures, ketones, anhydrides, esters, and the presence of carboxylic $\mathrm{C}$, or the presence of carbonaceous materials $(\mathrm{C}=\mathrm{C}$ and $\mathrm{C}=\mathrm{O}$ stretching; 1617 and $\left.1630 \mathrm{~cm}^{-1}\right) ; \mathrm{C}-\mathrm{C}$ alcoholic group stretching (1029-1169 $\mathrm{cm}^{-1}$ ); and lone aromatic $\mathrm{C}-\mathrm{H}$ out of the plane of vibration $\mathrm{CO}_{3}$ or $\mathrm{NO}_{3}$ (stretching between
804 to $870 \mathrm{~cm}^{-1}$ ) (Cui et al. 2019; Keiluweit et al. 2010; LibreTexts 2020; von Gunten et al. 2017). Finally, hemp biochar (Fig. 2d) contained: $\mathrm{N}-\mathrm{O}$ asymmetric stretching $\left(1540 \mathrm{~cm}^{-1}\right)$; phenolic (i.e., aromatic) or ketone structures $(\mathrm{O}-\mathrm{H}$ bending or $\mathrm{C}=\mathrm{O}$ stretching, respectively; 1405 and $1430 \mathrm{~cm}^{-1}$ ); and lone aromatic $\mathrm{C}-\mathrm{H}$ out of the plane of vibration $\mathrm{CO}_{3}$ or $\mathrm{NO}_{3}$ (stretching between 804 and $870 \mathrm{~cm}^{-1}$ ) (Keiluweit et al. 2010; LibreTexts 2020; von Gunten et al. 2017). Based on the above information, in general, the variety of functional groups present followed the order wheat straw biochar $>$ Kentucky bluegrass biochar $>$ hemp biochar $>$ lodgepole pine biochar.

Wheat straw, Kentucky bluegrass, and hemp biochars all contained aromatic functional groups, yet FTIR cannot distinguish between quantities present. Biochar aromaticity leads to the presence of delocalized $\pi$ electrons (Miles et al. 2016), and is typically more prevalent in biochars created at relatively high temperatures (Harvey et al. 2011). It is interesting to note that the lodgepole pine biochar was created at $700{ }^{\circ} \mathrm{C}$, yet apparently contained no 
aromatic structures, which may be why this biochar had a relatively high ORP. Wheat straw biochar was pyrolyzed at the lowest temperature of all biochars $\left(450^{\circ} \mathrm{C}\right)$, and thus had a relatively high ORP as compared to Kentucky bluegrass $\left(500^{\circ} \mathrm{C}\right)$ and hemp biochars $\left(500^{\circ} \mathrm{C}\right)$. The Kentucky bluegrass and hemp biochars had similar ORP values, and thus one might construe that both contained similar quantities of aromaticity.

\subsection{Timed batch adsorption experiment-all four biochars}

The amount of $\mathrm{Ca}, \mathrm{Mg}$, and $\mathrm{Na}$ either sorbed or released, and solution SAR, EC, and ORP, as a function of biochar type and time, is presented in Table 2. Except for EC, signifi-
$\mathrm{Mg}$ ) $<$ lodgepole pine biochar (sorbed $\mathrm{Mg}$ ) $<$ Kentucky bluegrass biochar (sorbed $\mathrm{Mg}$ ) $<$ wheat straw biochar (sorbed $\mathrm{Mg}$ ). Effects of biochar on Na sorption followed the order: wheat straw biochar (released $\mathrm{Na}$ ) $<$ lodgepole pine biochar (sorbed $\mathrm{Na}$ ) $<$ hemp biochar (sorbed $\mathrm{Na})<$ Kentucky bluegrass biochar (sorbed $\mathrm{Na}$ ). The above effects had a significant effect on the solution SAR, with the combination of releasing $\mathrm{Ca}$ and $\mathrm{Mg}$, and sorbing $\mathrm{Na}$, leading to the greatest reduction in SAR (from 8.8 to 8.0) with the hemp biochar. An identical response in $\mathrm{Ca}, \mathrm{Mg}$, and $\mathrm{Na}$ was observed with biochars used by She et al. (2018). Uchimiya et al. (2011b) noted that biochars can be a source of $\mathrm{Na}, \mathrm{Ca}$, and $\mathrm{Mg}$, with release affected by other non-biochar-borne cations in conjunction with biocharborne mineral dissolution and ion exchange. Finally, fewer

Table 2 Amount of $\mathrm{Ca}, \mathrm{Mg}$, and $\mathrm{Na}$ sorbed (positive values) or released (negative values) ( $\pm \mathrm{SE}$ mean) per mass of biochar from simulated saline irrigation water initially containing $42.5,33.4$, and $318 \mathrm{mg}$ of $\mathrm{Ca}, \mathrm{Mg}$, or $\mathrm{Na} \mathrm{L}^{-1}$, respectively

\begin{tabular}{|c|c|c|c|c|c|c|c|c|c|}
\hline \multirow{2}{*}{ Biochar Type } & \multicolumn{8}{|c|}{ Incubation time (h) } & \multirow{2}{*}{$\begin{array}{l}\text { Significance } \\
\text { Over Time }\end{array}$} \\
\hline & 1 & 2 & 4 & 8 & 16 & 24 & 96 & 168 & \\
\hline \multicolumn{10}{|l|}{ Wheat Straw } \\
\hline $\mathrm{Ca}\left(\mathrm{mg} \mathrm{kg}^{-1}\right)$ & $429 \pm 5$ & $452 \pm 25$ & $403 \pm 14$ & $418 \pm 12$ & $466 \pm 9$ & $468 \pm 14$ & $494 \pm 17$ & $498 \pm 21$ & B \\
\hline $\operatorname{Mg}\left(\mathrm{mg} \mathrm{kg}^{-1}\right)$ & $176 \pm 5$ & $190 \pm 7$ & $150 \pm 8$ & $160 \pm 11$ & $173 \pm 8$ & $190 \pm 6$ & $203 \pm 14$ & $216 \pm 11$ & A \\
\hline $\mathrm{Na}\left(\mathrm{mg} \mathrm{kg}^{-1}\right)$ & $-15 \pm 99$ & $-30 \pm 23$ & $-314 \pm 63$ & $-280 \pm 183$ & $-519 \pm 76$ & $-222 \pm 54$ & $-471 \pm 65$ & $-341 \pm 30$ & D \\
\hline SAR & $10.2 \pm 0.1$ & $10.3 \pm 0.1$ & $10.3 \pm 0.1$ & $10.4 \pm 0.1$ & $10.8 \pm 0.0$ & $10.5 \pm 0.1$ & $10.9 \pm 0.1$ & $10.8 \pm 0.1$ & A \\
\hline $\mathrm{EC}\left(\mathrm{dS} \mathrm{m} \mathrm{m}^{-1}\right)$ & $1.57 \pm 0.39$ & $1.65 \pm 0.25$ & $1.75 \pm 0.49$ & $1.53 \pm 0.18$ & $1.59 \pm 0.19$ & $1.66 \pm 0.15$ & $1.61 \pm 0.55$ & $0.69 \pm 0.18$ & A \\
\hline ORP (mV) & $281 \pm 8$ & $267 \pm 11$ & $278 \pm 10$ & $273 \pm 4$ & $303 \pm 7$ & $251 \pm 6$ & $273 \pm 15$ & $295 \pm 1$ & $\mathrm{E}$ \\
\hline \multicolumn{10}{|l|}{ Lodgepole Pine } \\
\hline $\mathrm{Ca}\left(\mathrm{mg} \mathrm{kg}^{-1}\right)$ & $-95 \pm 13$ & $-79 \pm 4$ & $-115 \pm 8$ & $-63 \pm 78$ & $-132 \pm 4$ & $-66 \pm 6$ & $-115 \pm 14$ & $-182 \pm 13$ & $\mathrm{D}$ \\
\hline $\operatorname{Mg}\left(\mathrm{mg} \mathrm{kg}^{-1}\right)$ & $93 \pm 6$ & $19 \pm 4$ & $-15 \pm 7$ & $20 \pm 5$ & $-21 \pm 2$ & $24 \pm 4$ & $-9 \pm 7$ & $-19 \pm 10$ & $\mathrm{C}$ \\
\hline $\mathrm{Na}\left(\mathrm{mg} \mathrm{kg}^{-1}\right)$ & $210 \pm 42$ & $340 \pm 29$ & $-36 \pm 84$ & $407 \pm 176$ & $-53 \pm 22$ & $316 \pm 45$ & $156 \pm 9$ & $148 \pm 64$ & $\mathrm{C}$ \\
\hline SAR & $8.5 \pm 0.0$ & $8.4 \pm 0.0$ & $8.6 \pm 0.1$ & $8.4 \pm 0.2$ & $8.6 \pm 0.0$ & $8.5 \pm 0.1$ & $8.5 \pm 0.0$ & $8.4 \pm 0.0$ & $\mathrm{C}$ \\
\hline $\mathrm{EC}\left(\mathrm{dS} \mathrm{m}{ }^{-1}\right)$ & $0.49 \pm 0.23$ & $1.18 \pm 0.03$ & $0.89 \pm 0.27$ & $1.06 \pm 0.37$ & $1.02 \pm 0.28$ & $0.92 \pm 0.13$ & $0.75 \pm 0.13$ & $0.75 \pm 0.11$ & B \\
\hline ORP (mV) & $361 \pm 5$ & $278 \pm 3$ & $284 \pm 12$ & $301 \pm 11$ & $304 \pm 9$ & $280 \pm 6$ & $274 \pm 26$ & $285 \pm 8$ & $A$ \\
\hline \multicolumn{10}{|l|}{ Kentucky bluegrass } \\
\hline $\mathrm{Ca}\left(\mathrm{mg} \mathrm{kg}^{-1}\right)$ & $524 \pm 54$ & $517 \pm 74$ & $567 \pm 28$ & $562 \pm 9$ & $798 \pm 64$ & $708 \pm 27$ & $630 \pm 16$ & $626 \pm 28$ & A \\
\hline $\operatorname{Mg}\left(\mathrm{mg} \mathrm{kg}^{-1}\right)$ & $132 \pm 22$ & $44 \pm 16$ & $167 \pm 13$ & $142 \pm 2$ & $136 \pm 28$ & $132 \pm 11$ & $-61 \pm 33$ & $-96 \pm 30$ & B \\
\hline $\mathrm{Na}\left(\mathrm{mg} \mathrm{kg}^{-1}\right)$ & $1060 \pm 144$ & $1090 \pm 265$ & $1030 \pm 74$ & $1080 \pm 32$ & $976 \pm 128$ & $1510 \pm 51$ & $1320 \pm 22$ & $1100 \pm 63$ & A \\
\hline SAR & $9.1 \pm 0.1$ & $8.7 \pm 0.2$ & $9.3 \pm 0.0$ & $9.2 \pm 0.0$ & $9.8 \pm 0.1$ & $9.0 \pm 0.1$ & $8.4 \pm 0.1$ & $8.5 \pm 0.1$ & B \\
\hline $\mathrm{EC}\left(\mathrm{dS} \mathrm{m}{ }^{-1}\right)$ & $1.45 \pm 0.16$ & $1.32 \pm 0.23$ & $0.97 \pm 0.06$ & $1.40 \pm 0.37$ & $1.27 \pm 0.13$ & $1.10 \pm 0.27$ & $1.32 \pm 0.12$ & $1.20 \pm 0.56$ & $\mathrm{AB}$ \\
\hline ORP (mV) & $236 \pm 4$ & $232 \pm 6$ & $249 \pm 4$ & $211 \pm 4$ & $243 \pm 1$ & $241 \pm 1$ & $189 \pm 18$ & $249 \pm 9$ & $\mathrm{c}$ \\
\hline \multicolumn{10}{|l|}{ Hemp } \\
\hline $\mathrm{Ca}\left(\mathrm{mg} \mathrm{kg}^{-1}\right)$ & $-115 \pm 1$ & $-60 \pm 24$ & $-150 \pm 12$ & $-103 \pm 18$ & $-108 \pm 9$ & $-64 \pm 4$ & $31 \pm 12$ & $43 \pm 30$ & $\mathrm{C}$ \\
\hline $\operatorname{Mg}\left(\mathrm{mg} \mathrm{kg}^{-1}\right)$ & $-13 \pm 10$ & $-24 \pm 6$ & $-38 \pm 4$ & $-6 \pm 15$ & $-63 \pm 1$ & $-37 \pm 3$ & $-19 \pm 6$ & $-26 \pm 16$ & D \\
\hline $\mathrm{Na}\left(\mathrm{mg} \mathrm{kg}^{-1}\right)$ & $808 \pm 71$ & $864 \pm 118$ & $416 \pm 92$ & $546 \pm 311$ & $384 \pm 21$ & $776 \pm 44$ & $907 \pm 8$ & $923 \pm 87$ & B \\
\hline SAR & $7.9 \pm 0.0$ & $7.9 \pm 0.1$ & $8.1 \pm 0.1$ & $8.2 \pm 0.3$ & $8.2 \pm 0.0$ & $7.9 \pm 0.0$ & $8.0 \pm 0.0$ & $8.0 \pm 0.0$ & D \\
\hline $\mathrm{EC}\left(\mathrm{dS} \mathrm{m} \mathrm{m}^{-1}\right)$ & $2.06 \pm 0.13$ & $0.88 \pm 0.41$ & $1.25 \pm 0.58$ & $1.36 \pm 0.36$ & $1.61 \pm 0.31$ & $1.18 \pm 0.28$ & $1.18 \pm 0.17$ & $1.22 \pm 0.12$ & A \\
\hline ORP (mV) & $213 \pm 2$ & $207 \pm 2$ & $228 \pm 6$ & $212 \pm 3$ & $209 \pm 1$ & $196 \pm 0$ & $200 \pm 3$ & $258 \pm 34$ & L \\
\hline
\end{tabular}

The sodium adsorption ratio (SAR), electrical conductivity (EC), and oxidation-reduction potential (ORP) are included as a reference; initial irrigation water SAR $=8.8$. Except for EC, significant biochar by time interactions existed for all constituents measured $(p<0.05)$ due to constituent fluctuations within the first $24 \mathrm{~h}$. Therefore, only significance averaged over time is presented, with different uppercase letters for an individual constituent indicating significant difference $(p<0.05)$ among biochars

cant biochar by time interactions existed for all constituents measured $(p<0.05)$ due to fluctuations present among all four biochars within the first $24 \mathrm{~h}$ of the study. For ease of data interpretation, only the significant averaged-over-time differences for individual constituents (i.e., $\mathrm{Ca}, \mathrm{Mg}, \mathrm{Na}$, SAR, EC, ORP) among biochars are presented.

Effects of biochar on Ca sorption followed the order: lodgepole pine biochar (released $\mathrm{Ca})<$ hemp biochar (released $\mathrm{Ca})<$ wheat straw biochar (sorbed $\mathrm{Ca}$ ) $<$ Kentucky bluegrass biochar (sorbed Ca). Effects of biochar on $\mathrm{Mg}$ sorption followed the order: hemp biochar (released differences in solution EC, as effected by biochar type, were observed. However, the effect of biochar on ORP followed the order: hemp biochar $<$ Kentucky bluegrass biochar $<$ wheat straw biochar $<$ lodgepole pine biochar. These observations were similar to those found in Fig. 1.

In the current study, wheat straw biochar appeared to have the greatest variety of functional groups available for ion exchange, yet performed poorly in terms of removing $\mathrm{Na}$ ions or releasing $\mathrm{Ca}$ and $\mathrm{Mg}$ ions, and reducing overall SAR. Wheat straw biochar increased solution SAR due to the sorption of $\mathrm{Ca}$ and $\mathrm{Mg}$ ions and release of $\mathrm{Na}$, with $\mathrm{Ca}$ and $\mathrm{Mg}$ 
sorption likely affected by the variety of organic functional groups present. Opposite, hemp biochar performed well in terms of removing $\mathrm{Na}$ ions and releasing $\mathrm{Ca}$ and $\mathrm{Mg}$ ions, reducing SAR to the greatest extent compared to other biochars. This was likely a function of aromaticity (e.g., phenolic groups present) leading to the presence of delocalized $\pi$ electrons, as reflected in the lowest ORP readings over the study period (Table 2). Zhu et al. (2004) noted that the relatively weak hydration of soft base cations (e.g., $\mathrm{Na}$ ), due to their relatively large radii, makes the cation $-\pi$ interaction more competitive in aqueous solutions. The authors further stated that hard base cations (e.g., $\mathrm{Ca}$ and $\mathrm{Mg}$ ) are expected to induce relatively weak cation $-\pi$ electron interactions because of their high hydrated energies; these cations form associations with biochar organic functional groups or form (hydr)oxide and carbonate mineral preciptates. Finally, Kentucky bluegrass biochar had an ORP similar to that of hemp biochar, suggestive of the same degree of aromaticity as hemp biochar, yet did not reduce solution SAR to the extent of hemp biochar. It is possible that cation- $\pi$ interactions were satisfied within Kentucky bluegrass biochar due to the initial $\mathrm{Na}$ content of at least an order of magnitude greater than hemp biochar (Table 1) in conjunction with soft cation $-\pi$ bonding as suggested by Zhu et al. (2004). Thus, the hemp biochar was utilized in a subsequent adsorbentdose batch experiment.

\subsection{Batch adsorption experiment-hemp biochar dosage}

The amount of $\mathrm{Ca}, \mathrm{Mg}$, and $\mathrm{Na}$ either sorbed or released, and solution SAR, EC, and ORP as a function of increasing hemp biochar application rate, is presented in Table 3. Increasing hemp biochar application rate significantly increased $\mathrm{Ca}$ and $\mathrm{Mg}$ sorption, yet even at the greatest hemp biochar application rate, this biochar was still releasing $\mathrm{Ca}$ and $\mathrm{Mg}$ into solution. The increase in $\mathrm{Ca}$ and $\mathrm{Mg}$ sorption may have been related to increasing organic functional groups present with increasing biochar application rates. Increasing hemp biochar application rate significantly increased $\mathrm{Na}$ sorption, likely due to $\mathrm{Na}-\pi$ bonding as suggested by Zhu et al. (2004). The significant reduction in solution $\mathrm{Na}$ content, likely due to electrostatic sorption, led to a significant decrease in solution SAR. The background solution SAR equaled 8.8 , while a $2.00 \mathrm{~g}$ of hemp biochar application to $25 \mathrm{~mL}$ of solution reduced the SAR to 7.3 , or a $17 \%$ decrease. The decrease was linear, suggesting that greater biochar application rates would reduce the SAR even further. Increasing hemp biochar application rate significantly increased solution EC, likely a function of greater $\mathrm{Ca}$ and $\mathrm{Mg}$ concentrations present. Finally, increasing hemp biochar application rate significantly reduced the ORP. The reduction in ORP, in combination with increased Na sorption, further suggests that increasing hemp biochar application rate increases the quantity of $\pi$ electrons present, aiding in the $\mathrm{SAR}$ reduction.

\subsection{Sodium adsorption isotherms onto hemp biochar}

The Langmuir and Freundlich isotherm models were used to determine if $\mathrm{Na}$ adsorption onto hemp biochar was occurring via monolayer (i.e., Langmuir) or multilayer (i.e., Freundlich) formation. Sodium adsorption via the linear forms of both models is presented in Fig. 3a, b. The Langmuir model fit the data better $\left(R^{2}=0.9085\right)$ as compared to the Freundlich model $\left(R^{2}=0.4640\right)$, suggesting Na monolayer sorption. Lu et al. (2012) stated that mono-valent cations should be related to electrostatic ion exchange since they cannot be coordinated with biochar surface functional groups or form mineral precipitates; this statement further supports Na monolayer formation on hemp biochar.

Safari et al. (2019) utilized Langmuir and Freundlich isotherms to study $\mathrm{Cu}$ sorption (a hard cation) onto biochar. The authors noted that the Freundlich model provided a higher correlation coefficient than the Langmuir

simulated saline irrigation water initially containing $42.5,33.4$, and $318 \mathrm{mg}$ of $\mathrm{Ca}, \mathrm{Mg}$, or $\mathrm{Na} \mathrm{L}^{-1}$, respectively and an initial SAR, EC, and ORP of $8.8,1.65 \mathrm{dS} \mathrm{m}^{-1}$, and $342 \mathrm{mV}$, respectively
Table 3 Amount of $\mathrm{Ca}, \mathrm{Mg}$, and $\mathrm{Na}$ sorbed (positive values) or released (negative values), sodium adsorption ratio (SAR), electrical conductivity (EC), and oxidation-reduction potential (ORP) ( \pm SE Mean) after increasing hemp biochar $(\mathrm{g})$ addition to $25 \mathrm{~mL}$ of

\begin{tabular}{lllllll}
\hline $\begin{array}{l}\text { Hemp biochar applica- } \\
\text { tion rate }(\mathrm{g})\end{array}$ & $\begin{array}{l}\mathrm{Ca} \\
\left(\mathrm{mg} \mathrm{kg}^{-1}\right)\end{array}$ & $\mathrm{Mg}$ & $\mathrm{Na}$ & $\mathrm{SAR}$ & $\begin{array}{l}\mathrm{EC} \\
\left.(\mathrm{dS} \mathrm{m})^{-1}\right)\end{array}$ \\
\hline 0.25 & $-704 \pm 10 \mathrm{c}$ & $-265 \pm 18 \mathrm{~b}$ & $-487 \pm 136 \mathrm{a}$ & $8.5 \pm 0.0 \mathrm{a}$ & $\begin{array}{l}\text { ORP } \\
(\mathrm{mV})\end{array}$ \\
0.50 & $-468 \pm 14 \mathrm{bc}$ & $-166 \pm 1 \mathrm{ab}$ & $-245 \pm 102 \mathrm{a}$ & $8.3 \pm 0.0 \mathrm{a}$ & $2.34 \pm 0.02 \mathrm{c}$ & $221 \pm 4 \mathrm{a}$ \\
1.00 & $-289 \pm 9 \mathrm{ab}$ & $-107 \pm 3 \mathrm{a}$ & $-38 \pm 72 \mathrm{a}$ & $8.1 \pm 0.1 \mathrm{~b}$ & $2.66 \pm 0.04 \mathrm{abc}$ & $206 \pm 10 \mathrm{ab}$ \\
1.50 & $-197 \pm 23 \mathrm{a}$ & $-56 \pm 11 \mathrm{ab}$ & $304 \pm 99 \mathrm{~b}$ & $7.7 \pm 0.1 \mathrm{c}$ & $2.83 \pm 0.24 \mathrm{ab}$ & $178 \pm 3 \mathrm{~cd}$ \\
2.00 & $-171 \pm 12 \mathrm{a}$ & $-40 \pm 2 \mathrm{~b}$ & $379 \pm 24 \mathrm{c}$ & $7.3 \pm 0.0 \mathrm{~d}$ & $3.04 \pm 0.32 \mathrm{a}$ & $173 \pm 2 \mathrm{~d}$ \\
\hline
\end{tabular}

Solutions were allowed to stand undisturbed on a lab bench for $1 \mathrm{~h}$. Different lowercase letters for an individual constituent indicating significant difference $(p<0.05)$ 
model, suggestive of multilayer sorption onto heterogeneous biochar organic colloidal phases. Safari et al. (2019) further showed that $\mathrm{Cu}$ sorption was driven by the abundance of biochar-borne carboxyl and hydroxyl groups present. Similarly, Lu et al. (2012) studied $\mathrm{Pb}$ (an intermediate cation; i.e., between hard and soft) sorption via biochar, also observing carboxyl and hydroxyl functional groups affecting $\mathrm{Pb}$ sorption, with carboxyl groups playing a more significant role. The authors noted, however, that co-precipitation and complexation on biochar surfaces led to $\mathrm{Ca}$ and $\mathrm{Mg}$ release during sorption, with $\mathrm{Ca}$ and $\mathrm{Mg}$ sorption/desorption characteristics related to biochar surface functional group complexation or $\mathrm{Ca}$ and $\mathrm{Mg}$ mineral precipitation/dissolution reactions. These findings, in combination with those of Lu et al. (2012) that stated Na ions are held on biochar surfaces via electrostatic interactions (i.e., $\pi$ electrons), support the contention that biochars created to contain greater delocalized $\pi$ electrons (e.g., lower ORP) may sorb mono-valent, soft base cations to a greater degree than biochars containing an abundance of organic
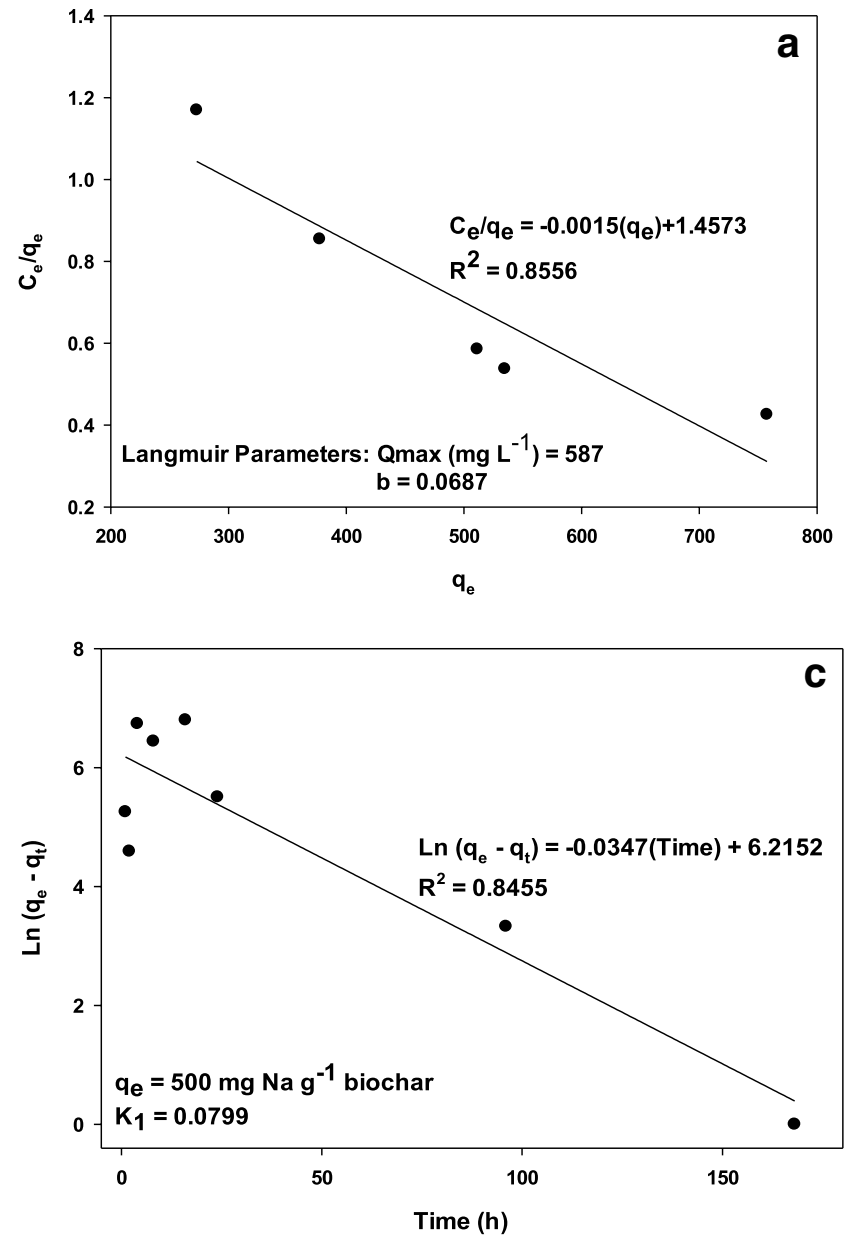

functional groups or that have the ability to form mineral precipitation reactions. Understanding sorption phenomenon, in conjunction with initial biochar Na content, supports the contention that $\pi$ electrons are responsible for hemp biochar Na sorption, leading to potential $\mathrm{Na}$ removal from Na-containing water bodies.

\subsection{Sodium adsorption kinetics onto hemp biochar}

Pseudo-first-order and pseudo-second-order kinetic models can be used to support physisorption or chemisorption in conjunction with diffusion-limited processes, or processes that describe weak electrostatic interactions versus adsorbates becoming covalently bound to adsorbents, respectively (Hubbe et al. 2019; Sims et al. 2019). Sodium adsorption kinetics via the use of these two models is presented in Fig. 3c, d. The pseudo-first- and second-order models fit $\mathrm{Na}$ adsorption well, although the pseudo-second-order model had a greater fit $\left(R^{2}=0.9852\right.$ versus 0.8455$)$, suggesting that
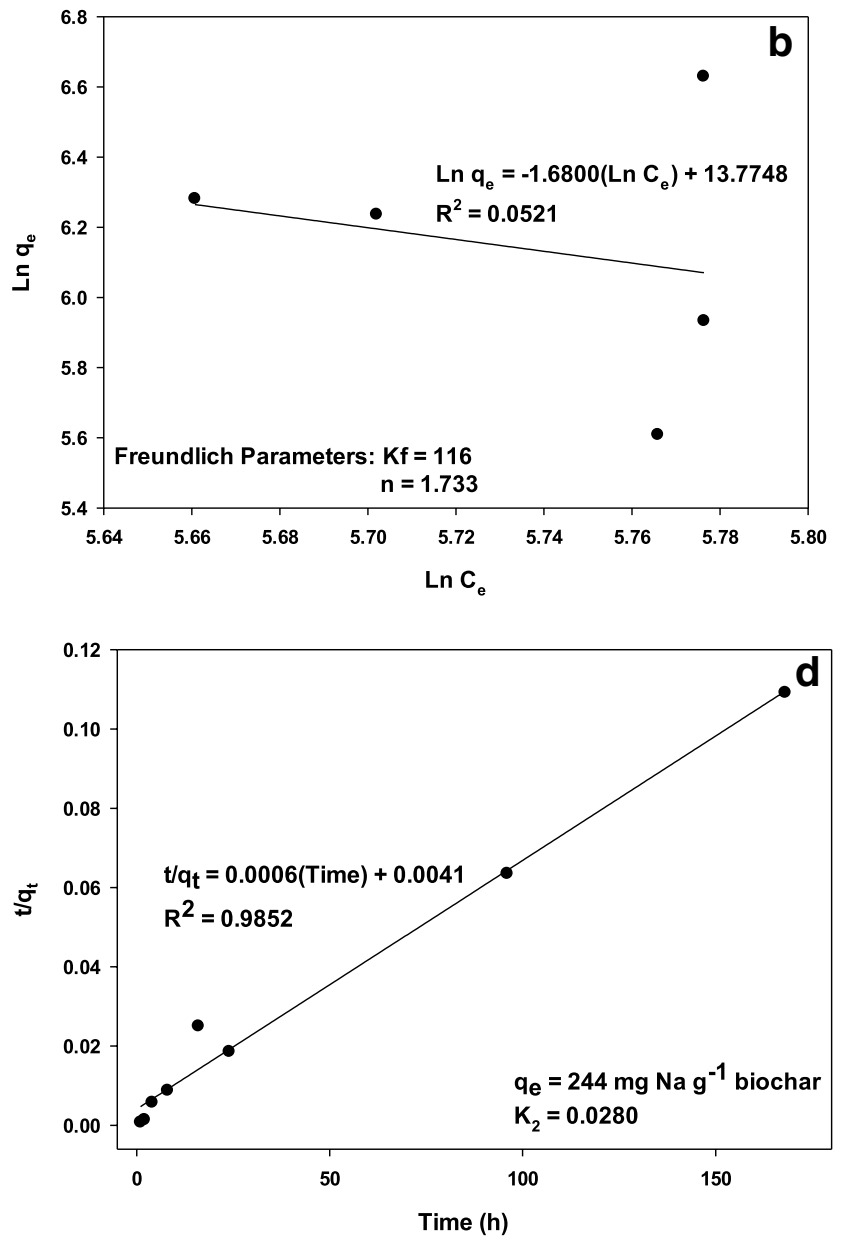

Fig. 3 Sodium adsorption onto hemp biochar as described by the a linear Langmuir adsorption, b linear Freundlich adsorption, $\mathbf{c}$ pseudo-firstorder kinetics, and d pseudo-second-order kinetics models 
chemisorption or diffusion processes play a greater role in $\mathrm{Na}$ adsorption onto hemp biochar.

Safari et al. (2019) showed that $\mathrm{Cu}$ sorption followed pseudo-second-order kinetics, correlated to the presence of carboxyl and hydroxyl groups. Ding et al. (2014) found that the pseudo-second-order model fit $\mathrm{Pb}$ sorption onto biochar better than a pseudo-first-order model, with $\mathrm{Pb}$ sorption a rate-limited process. Shen et al. (2015) found that a pseudosecond-order model fit $\mathrm{Pb}$ sorption onto biochar, suggesting chemisorption onto biochar surfaces. Pseudo-second-order chemisorption involves the sharing or exchange of electrons between adsorbent and adsorbate (Deng et al. 2009), which is not the case if cations such as $\mathrm{Na}$ are electrostatically attracted to $\pi$ electrons.

The following discussion attempts to discern Na physisorption (onto biochar surfaces via $\pi$ bonding; physisorption) and diffusion (into biochar pores; chemisorption) mechanisms occurring with hemp biochar. Li et al. (2010) studied sodium dodecyl sulfate sorption onto a hydrocarbon nanoporous polymer. The authors noted that physisorption along with the Langmuir isotherm described $\mathrm{Na}$ adsorption well, both of which support the current study findings that $\mathrm{Na}$ interactions via electrostatic interactions with aromatically derived $\pi$ electrons. Klüpfel et al. (2014) noted that biochars can reversibly accept or donate up to $2 \mathrm{mmol} \mathrm{e}^{-} \mathrm{g}^{-1}$ biochar. However, Prévoteau et al. (2016) showed that the electron donating capacity of biochars produced at 400,500 , or $600{ }^{\circ} \mathrm{C}$ was $\sim 7,3.5$, and

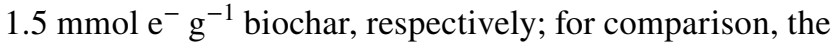
hemp biochar used in the current study was pyrolyzed at $500{ }^{\circ} \mathrm{C}$. Over the $168 \mathrm{~h}$ batch experiment, hemp biochar sorbed between 1.11 and $2.68 \mathrm{mmol} \mathrm{Na} \mathrm{g} \mathrm{g}^{-1}$ biochar, in agreement with the findings of Klüpfel et al. (2014) and Prévoteau et al. (2016). This finding suggests that physisorption was likely occurring, even though chemisorption was suggested to occur by the pseudo-second-order rate equation. In support of physisorption occurring to a greater extent over chemisorption, Prévoteau et al. (2016) attributed greater biochar physisorption via electron donating capacity (over that described by Klüpfel et al. 2014) to unnoticed slow kinetics of electron transfer from biochar surfaces, which in theory would be accounted for in pseudo-second-order kinetic model. Yet, we still cannot entirely rule out both physisorption and chemisorption occurring simultaneously. For example, Yun et al. (2015) noted both physisorption and chemisorption of $\mathrm{Na}$ on $\mathrm{C}$ nanoplates; physisorption was possible if electrostatic charges were accumulated at the nanoplate surface, while chemisorption could occur at plate defect sites or diffusion-limited reactions. The explanation by Yun et al. (2015) may support both sorption processes as related to the current study's conflicting Langmuir and pseudo-second-order kinetic model evidence. However, data from the current study more strongly support physisorption mechanisms behind $\mathrm{Na}$ sorption onto hemp biochar.

\section{Conclusions}

Four biochars, containing varying organic functional groups and electrochemistries, were utilized to potentially reduce SAR from simulated irrigation water. Hemp biochar showed the most promise for improving simulated irrigation water SAR by sorbing $\mathrm{Na}$ and releasing $\mathrm{Ca}$ and $\mathrm{Mg}$ ions into solution. Sodium adsorption increased with increasing hemp biochar application rate. Adsorption isotherms, in conjunction with kinetic modeling, suggested that Na sorption onto hemp biochar was governed by monolayer interactions and physisorption processes, both of which suggest $\mathrm{Na}$ adsorption is governed by electrostatic interactions with hemp biochar. It also appeared that $\mathrm{Na}$ diffusion into hemp biochar pores played a sorption role. However, based on hemp biochar ORP, findings suggest that Na sorption was predominantly driven by $\pi$ electron interactions. Therefore, we accepted the hypothesis that biochars with greater electronegativity led to greater $\mathrm{Na}$ adsorption (as long as the initial biochar did not contain appreciable $\mathrm{Na}$ ) and subsequently led to a greater reduction in water SAR. In the future, biochars could be designed to have properties (e.g., low ORP and low Na concentrations) similar to or in exceedance of hemp biochar, to reduce irrigation water SAR and subsequently improve crop growth.

Acknowledgements Major financial support for this study was provided by a grant from the US Agency for International Development through the US-Pakistan Centers for Advanced Studies in Water (10035947-S1). We gratefully thank the US-Pakistan Center for Advanced Studies in Water, Mehran University of Engineering and Technology Jamshoro and USAID for funding this project. We also want to thank the Salinity Control and Reclamation Project, Pakistan Water and Power Development Authority for providing us the water quality data set, as without the help of these departments this research could not have been possible. Finally, we thank the Department of Soil and Crop Sciences at Colorado State University, and in particular, Dr. Jim Ippolito's research laboratory for providing research guidance.

Open Access This article is licensed under a Creative Commons Attribution 4.0 International License, which permits use, sharing, adaptation, distribution and reproduction in any medium or format, as long as you give appropriate credit to the original author(s) and the source, provide a link to the Creative Commons licence, and indicate if changes were made. The images or other third party material in this article are included in the article's Creative Commons licence, unless indicated otherwise in a credit line to the material. If material is not included in the article's Creative Commons licence and your intended use is not permitted by statutory regulation or exceeds the permitted use, you will need to obtain permission directly from the copyright holder. To view a copy of this licence, visit http://creativecommons.org/licenses/by/4.0/. 


\section{References}

Abulnour AG, Sorour MH, Talaat HA (2002) Comparative economics for desalting of agricultural drainage water (ADW). Desalinization 152:353-357

Akhtar SS, Andersen M, Liu F (2015) Biochar mitigates salinity stress in potato. J Ag Crop Sci 201:368-378

Congress.gov (1974) H.R.12165-Colorado River Basin Salinity Control Act. https://www.congress.gov/bill/93rd-congress/ house-bill/12165. Accessed 16 September 2020

Cui L, Yin C, Chen T, Quan G, Ippolito JA, Gan H, Xiao B, Pan M, Lui B, Yan J, Ding C, Hussain Q, Umer M (2019) Remediation of organic halogen- contaminated wetland soil using biochar. Sci Tot Environ 696:134087

Deng S, Ma R, Yu Q, Huang J, Yu G (2009) Enhanced removal of pentachlorophenol and 2,4-D from aqueous solution by an aminated biosorbent. J Hazard Mater 165:408-414

Ding W, Dong X, Ime IM, Gao B, Ma LQ (2014) Pyrolytic temperatures impact lead sorption mechanisms by bagasse biochars. Chemosphere 105:68-74

Elshaikh NA, She D (2018) Decreasing the salt leaching fraction and enhancing water-use efficiency for okra using biochar amendments. Commun Soil Sci Plant Anal 49:225-236

Food and Agriculture Organization (FAO) of the United Nations (2017) Water for sustainable food and agriculture. A report produced for the G20 Presidency of Germany. https://www.fao. org/3/a-i7959e.pdf. Accessed 16 September 2020

Godfray HCJ, Beddington JR, Crute IR, Haddad L, Lawrence D, Muir JF, Pretty J, Robinson S, Thomas SM, Toulmin C (2010) Food security: the challenge of feeding 9 billion people. Science 327:812-818

Harvey OR, Herbert BE, Rhue RD, Kuo LJ (2011) Metal interactions at the biochar-water interface: energetics and structure-sorption relationships elucidated by flow adsorption microcalorimetry. Environ Sci Technol 45:5550-5556

Hubbe MA, Azizian S, Douven S (2019) Implications of apparent pseudo-second-order adsorption kinetics onto cellulosic materials: a review. Bioresouces.com 14:7582-7626

Kaner A, Tripler E, Hadas E, Ben-Gal A (2017) Feasibility of desalinization as an alternative to irrigation with water high in salts. Desalinization 416:122-128

Keiluweit M, Nico PS, Johnson MG, Kleber M (2010) Dynamic molecular structure of plant biomass-derived black carbon (biochar). Environ Sci Technol 44:1247-1253

Klüpfel L, Keiluweit M, Kleber M, Sander M (2014) Redox properties of plant biomass-derived black carbon (biochar). Environ Sci Technol 48:5601-5611

Langmuir I (1916) The constitution and fundamental properties of solids and liquids. J Am Chem Soc 38:2221-2295

Lehmann J, Joseph S (2009) Biochar for environmental management: an introduction. In: Lehmann J, Joseph S (eds) Biochar for environmental management: science and technology. Earthscan, London, pp 1-12

Li L, Wang Y, Vigild ME, Ndoni S (2010) Physisorption of SDS in a hydrocarbon nanoporous polymer. Langmuir 26:13457-13465

LibreTexts (2020) Infrared: Interpretation. https://chem.libretexts .org/Bookshelves/Physical_and_Theoretical_Chemistry_Textb ook_Maps/Supplemental_Modules_(Physical_and_Theoretica 1_Chemistry)/Spectroscopy/Vibrational_Spectroscopy/Infra red_Spectroscopy/Infrared\%3A_Interpretation. Accessed 16 September 2020

Limousin G, Gaudet JP, Charlet L, Szenknect S, Barthes V, Krimissa M (2007) Sorption isotherms: a review on physical bases, modelling and measurement. Appl Geochem 22:249-275
Lu HL, Zhang WH, Yang YX, Huang XF, Wang SZ, Qui RL (2012) Relative distribution of $\mathrm{Pb}^{2+}$ sorption mechanisms by sludgederived biochar. Water Res 46:854-862

Marshall E (1985) San Joaquin flooded with water researchers: environmentalists link up with an irrigation district to propose a desalting plant for removing agricultural wastes. Science 230:920-921

Michelsen AM, McGuckin T, Sheng Z, Lacewell R, Creel B (2009) Rio Grande Salinity management program: Preliminary economic impact assessment. Texas AgriLife, Texas A\&M University. https ://agrilifecdn.tamu.edu/elpaso/files/2011/10/Rio-Grande-SalinityPreliminary-Economic-Assessment-Report-Dec-2009-Final.pdf. Accessed 16 September 2020

Miles TR, Rasmussen EM, Gray M (2016) Aqueous contaminant removal and stormwater treatment using biochar. In: Guo M, He Z, Uchimiya SM (eds) Agricultural and environmental applications of biochar: advances and barriers. Soil Science Society of America Special Publication 63, Madison, pp 341-376

Mueller ND, Gerber JS, Johnston M, Ray DK, Ramankutty N, Foley JA (2012) Closing yield gaps through nutrient and water management. Nature 490:254

Nelson DW, Sommers LE (1996) Total C, organic C, and organic matter. In: Sparks DL (ed) Methods of soil analysis, Part 3-chemical methods. Soil Science Society of America, Madison, pp 975-977

Ormbsy LS (1985) Method of removing salts of the alkali earth metal group from water. United States Patent Number 4,500,433. https:// patentimages.storage.googleapis.com/24/56/33/d790a8431a1944/ US4500433.pdf. Accessed 16 September 2020

Phillips FM, Mills S, Hendrickx MH, Hogan J (2003) Environmental tracers applied to quantifying causes of salinity in arid-region rivers: results from the Rio Grande Basin, Southwestern USA. Develop Water Sci 50:327-334

Prévoteau A, Ronsse F, Cid I, Boeckx P, Rabaey K (2016) The electron donating capacity of biochar is dramatically underestimated. Sci Reports 6:32870

Qureshi AS, McCornick PG, Qadir M, Aslam Z (2008) Managing salinity and waterlogging in the Indus Basin of Pakistan. Ag Water Manage 5:1-10

Rezaie N, Razzaghi F, Sepashkhah AR (2019) Different levels of irrigation water salinity and biochar influence on faba bean yield, water productivity, and ions uptake. Commun Soil Sci Plant Anal 50:611-626

Ritchie H, Roser M (2018) Water use and stress. https://ourworldindata. org/water-use-stress. Accessed 16 September 2020

Safari S, von Gunten K, Alam MdS, Hubmann M, Blewett TA, Chi Z, Alessi DS (2019) Biochar colloids and their use in contaminants removal. Biochar 1:151-162

SAS Institute (2012) SAS/STAT user's guide. Version 9.4. SAS Inst., Cary, NC

SAS Institute (2013) SAS/STAT 13.1 User's guide: The ANOVA procedure. https://support.sas.com/documentation/onlinedoc/ stat/131/anova.pdf. Accessed 16 September 2020

She D, Sun X, Gamareldawla AHD, Nazar EA, Hu W, Edith K, Yu S (2018) Benefits of soil biochar amendments to tomato growth under saline water irrigation. Sci Rep 8:14743

Shen Z, Jin F, Wang F, McMillan O, Al-Tabbaa A (2015) Sorption of lead by Salisbury biochar produced from British broadleaf hardwood. Bioresource Technol 193:553-556

Sims RA, Harmer SL, Quinton JS (2019) The role of physisorption and chemisorption in the oscillary adsorption of organisilanes on aluminium oxide. Polymers 11:410

Soltanpour PN, Johnson GW, Workman SM, Jones JB Jr, Miller RO (1996) Inductively coupled plasma emission spectrometry and inductively coupled plasma-mass spectrometry. In: Sparks DL (ed) Methods of soil analysis, Part 3-chemical methods. Soil Science Society of America, Madison, pp 91-139 
Uchimiya M, Chang S, Klasson KT (2011) Screening biochars for heavy metal retention in soil: role of oxygen functional groups. J Hazard Mater 190:432-441

Uchimiya M, Klasson KT, Wartelle LH, Lima IM (2011) Influence of soil properties on heavy metal sequestration by biochar amendment: 1. Copper sorption isotherms and the release of cations. Chemosphere 82:1431-1437

Uchimiya M, Cantrell KB, Hunt PG, Novak JM, Chang S (2012) Retention of heavy metals in a Typic Kandiudult amended with different manure-based biochars. J Environ Qual 41:1138-1149

United Nations (2017) World population prospects. https://population .un.org/wpp/Publications/Files/WPP2017_KeyFindings.pdf. Accessed 16 September 2020

U.S. Bureau of Land Reclamation (2010) Central Arizona salinity study-Phase 1. Technical Appendix A. Salinity and total dissolved solids. https://www.usbr.gov/lc/phoenix/programs/cass/ pdf/Phase1/ATechapdxTDS.pdf. Accessed 16 September 2020

von Gunten K, Alam MdS, Hubmann M, Ok YS, Konhauser KO, Alessi DS (2017) Modified sequential extraction for biochar and petroleum coke: metal release potential and its environmental implications. Bioresource Technol 236:106-110

Yang YN, Sheng Q, Zhang L, Kang HQ, Liu Y (2015) Desalinization of saline farmland drainage water through wetland plants. $\mathrm{Ag}$ Water Manage 156:19-29

Yang R, Zhou C, Zhu J, Pan Y, Sun J, Zhang Z (2019) Effects of biochar application on phreatic water evaporation and water-salt distribution in coastal saline soil. J Plant Nutr 42:1243-1253

Yuan Y, Bolan N, Prévoteau A, Vithanage M, Biswas JK, Ok YS, Wang $\mathrm{H}$ (2017) Applications of biochar in redox-mediated reactions. Bioresource Technol 246:271-281

Yun YS, Park K-Y, Lee B, Cho SY, Park Y-U, Hong SJ, Kim BH, Gwon H, Kim H, Lee S, Park YW, Jin H-J, Kand K (2015) Sodiumion storage in pryoprotein-based carbon nanoplates. Adv Mater 27:6914-6921

Zhu D, Herbert BE, Schlautman MA, Carraway ER, Hur J (2004) Cation- $\pi$ bonding: a new perspective on the sorption of polycyclic aromatic hydrocarbons to mineral surfaces. J Environ Qual 33:1322-1330 